\title{
Why are Phragmites australis Canes Grown in an Udono Reed Bed the Best for Reeds of the Japanese Wind Instrument Hichiriki?: A Structural and Biomechanical Study
}

\author{
Masahiro Kawasaki, ${ }^{1 *}$ Tadashi Nobuchi, ${ }^{\dagger \dagger}$ Masateru Nose, ${ }^{3}$ and Makoto Shiojiri ${ }^{4 \# *}$ \\ ${ }^{1}$ JEOL USA Inc., 11 Dearborn Road, Peabody, MA 01960 \\ ${ }^{2}$ Kyoto University, Kyoto 606-8501, Japan \\ ${ }^{3}$ Faculty of Art and Design, University of Toyama, Takaoka, Toyama 933-8588, Japan \\ ${ }^{4}$ Kyoto Institute of Technology, Kyoto 606-8585, Japan \\ ${ }^{\dagger}$ Present address: 1-68 Kunobe, Shiga, 520-2353, Japan \\ \#Present address: 1-297 Wakiyama, Kyoto 618-0091, Japan \\ *kawasaki@jeol.com
}

\begin{abstract}
The hichiriki is a Japanese double-reed wind instrument used in 7 th century imperial court music. For more than 1,200 years the best hichiriki reeds have been made only from canes of the reed plant $P$. australis harvested from riverside reed beds near Kyoto. Because these reed beds are now endangered, investigations were undertaken on plant anatomy and mechanical behavior of tissues from canes of various localities. Biomechanics measurements were taken of certain tissue features to determine the cane characteristics that produce the best reeds.
\end{abstract}

\section{Introduction}

Gagaku is the Japanese ancient imperial court music from the 7 th century and was added in 2009 to the UNESCO list of masterpieces of the Intangible Cultural Heritage of Humanity [1]. Hichiriki, shown in Figure 1, is a Japanese double-reed woodwind instrument, or flageolet, which usually performs the main melody of a gagaku piece [2]. (Listen to the hichiriki online in the digital edition of this issue at this web address: http://dx.doi. org/10.1017/S1551929516000110). A reed is a thin strip of material that vibrates to produce a sound by setting oscillation in the air column inside the tube of a wind instrument, such as clarinet, saxophone, oboe, bassoon, and hichiriki. The reed plant Phragmites australis ( $P$. australis, common reed) commonly grows in wetlands in wide regions of the world. Although it can be found in reed beds along many rivers and lakesides in Japan, for more than 1,200 years the best reeds for the hichiriki have been made only out of canes of $P$. australis harvested from Udono (pronouced as [udono]), which is a limited reed bed of riverbanks located south of the border between Kyoto and Osaka along the Yodo River (Figure 2). This situation resembles that in which the best reeds for clarinet, oboe, or bassoon are manufactured from a cane of Arundo donax (A. donax, giant reed) that grows only in a few areas in the Var in southeastern France where the Mediterranean climate is very mild. Now, environmental disruption in Udono endangers the $P$. australis for hichiriki reeds and may bring a catastrophic crisis to gagaku. The International Double Reed Society, with members in more than 50 countries, expressed support for the call to protect and preserve the riverbanks of Udono, where the soul of hichiriki resides [3].

Plant anatomy and physical properties of $A$. donax related to the musical performance of the reeds of wind instruments such as clarinet, oboe, and bassoon have been studied by many researchers [4-12]. However, there are few papers regarding the plant anatomy and biomechanics of $P$. australis or hichiriki reeds (rozetsu in Japanese).
In this article, we review our recent investigation of plant anatomy and morphology for selected canes of $P$. australis grown in different reed beds in Japan. Moreover, the local indentation hardness and Young's modulus were measured for different

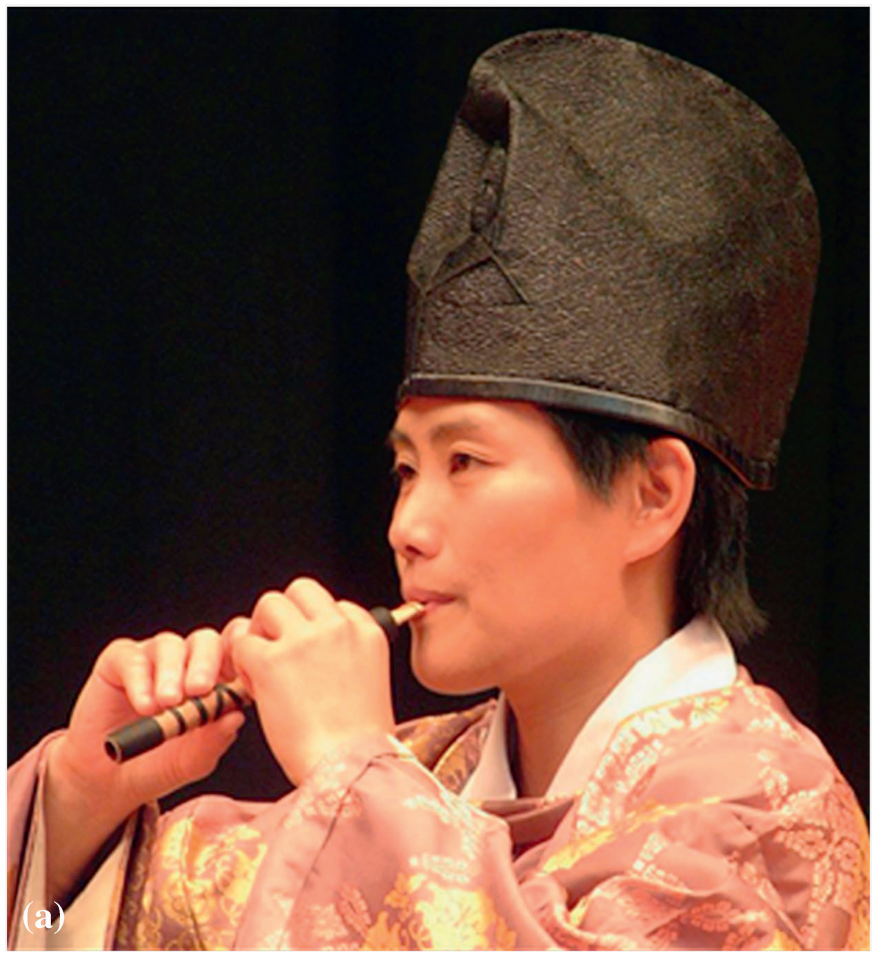

Seme: An adjuster placed to control the space between two blades.

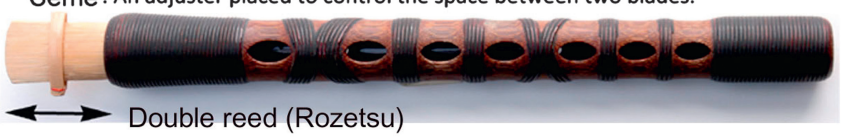

(b)

Figure 1: (a) Playing hichiriki (photograph taken by Katsuhiko Tabuchi). (b) Hichiriki (photogragh taken by Hitomi Nakamura). The length of the hichiriki is about $180 \mathrm{~mm}$. The reed used in hichiriki is called rozetsu in Japanese. An adjuster to control the space between two blades is called seme. 


\section{당
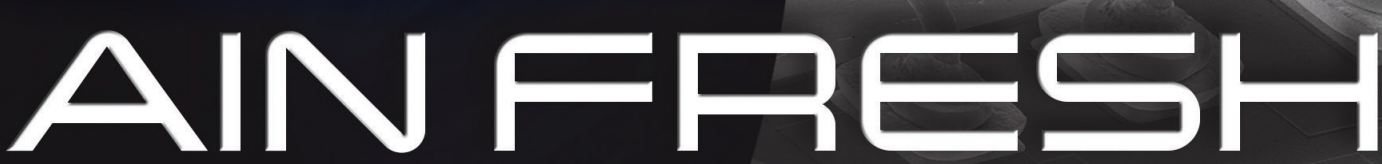

IN
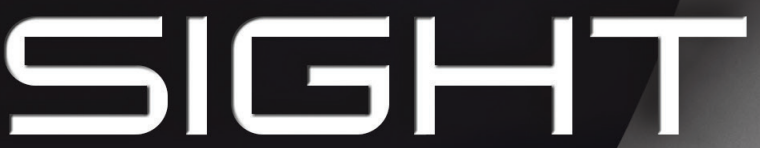

$100 \mu \mathrm{m}$

IMAGING AND ANALYSIS

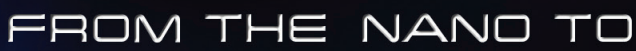
MAடค口 தடAடE

$y^{2}=100 \mathrm{~nm}$

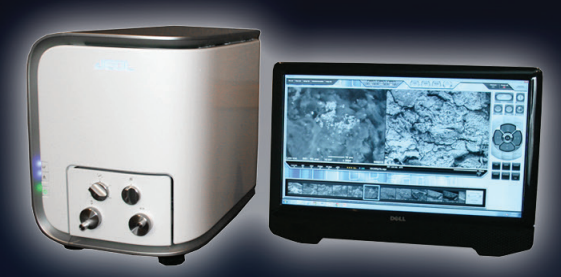

NEW!

JCM-6000Plus NeoScope -

10X-60,000X, SE-BSE-EDS, LV/HV

\section{Call us for a demo today!} See our full suite of JEOL SEMS.

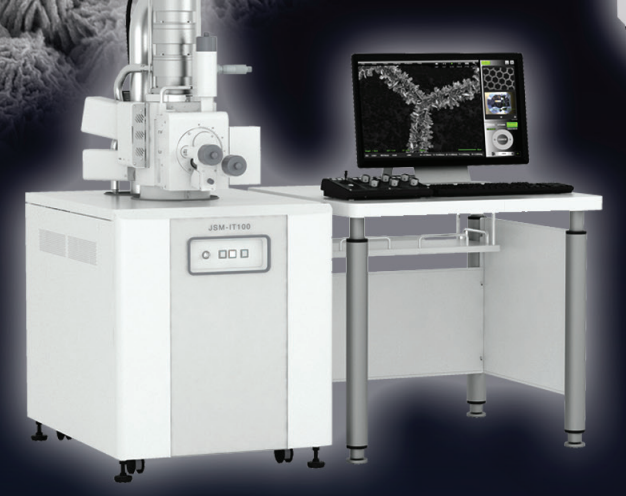

NEW!

JSM-IT100 -

up to $300,000 X$, SE-BSE-EDS,

LV/HV, versatile compact SEM

$\operatorname{cosen} x$ * *
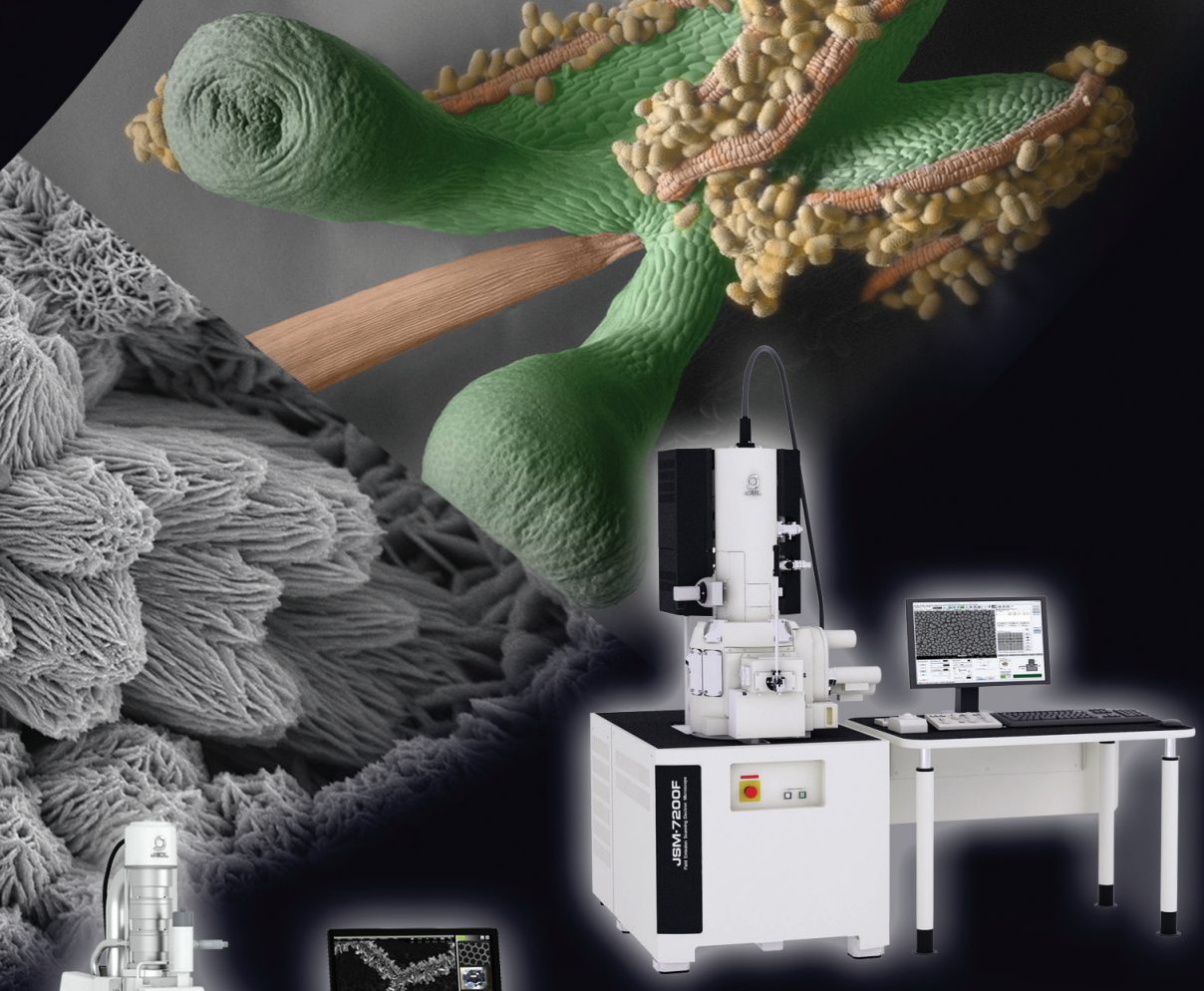

NEW!

JSM-7200F -

$10 X$ to $1,000,000 X$, compact nanolaboratory, ultrahigh resolution FE SEM

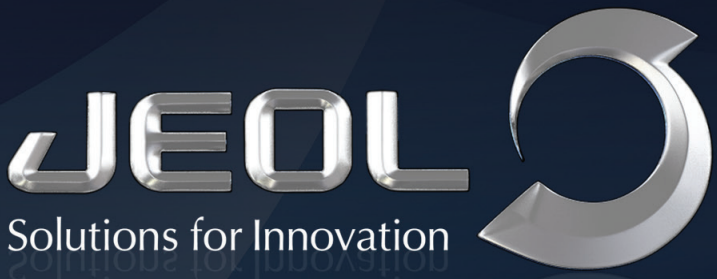

www.jeolusa.com • salesinfo@jeol.com 
tissues on cross sections of representative hichiriki reeds, rozetsu [13]. We were searching for the reason the $P$. australis canes from Udono along the Yodo River are the best materials for rozetsu. A geographical answer may also be necessary, considering envelopments for the growth of $P$. australis, such as soil, quantity and quality of the river water, and climate, as well as social priorities, such as traditional monopolies for the cultivation and distribution of reeds
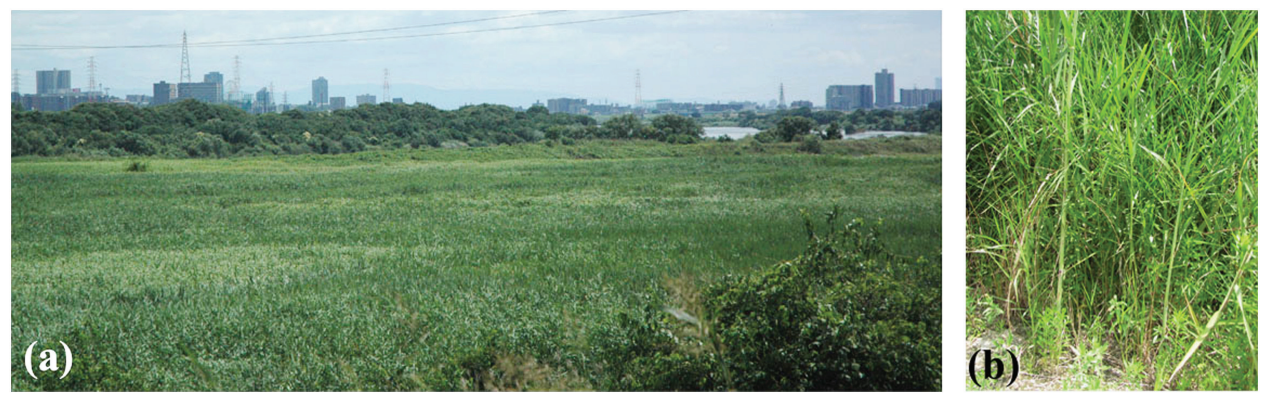

Figure 2: (a) Udono, a reed bed of the riverbanks near Kyoto along the Yodo River, which is seen upper right. (b) Young grasses of Phragmites australis. Photographs were taken by Makoto Shiojiri in June 2015.

generated from Kyoto, the Imperial Capital of Japan for over 1,000 years. However, the first step toward the answer is to examine the differences in the structure of the $P$. australis grown in Udono compared with those grown in other areas. We develop this discussion in a later section of this article with the results from our new investigation on the plant anatomy and biomechanics of clarinet reeds.

\section{Materials and Methods}

Various canes of $P$. australis were sampled from five reed beds along different Japanese rivers: the Kitakami River, the Watarase River, the Turumi River, the Uji River, and the Yodo River. A reed bed along the Yodo River is particularly called Udono. Those canes were examined for their utility in producing rozetsu and were used for the present plant anatomy observations [13]. We selected an appropriate internode (about $11 \mathrm{~mm}$ in outer diameter) from each cane in the same way that a reed producer would choose it as material for rozetsu. Specimens for light microscopy were prepared first by cutting the selected internodes to transverse sections of about $30 \mu \mathrm{m}$ in thickness with a sliding microtome, followed by conventional double staining with safranin and fast green FCF. Then the sections were mounted with Canada balsam as specimens for observation.

For biomechanical measurements, we obtained three pieces of rozetsu that were made of the canes carefully harvested from Udono and one from a reed bed of Kitakami River. Each was crafted and examined for musical performance by a hichiriki player (who routinely handcrafts rozetsu [14]). Hardness and Young's modulus were measured for each specimen, prepared by cutting a section out of the bottom part of rozetsu in the transverse plane for observation of the whole cross section, followed by embedding the cut piece in the epoxy resin and polishing it successively with a series of wet sandpaper sheets of finer grades (\#320, \#400, and \#600) on a glass plate to create a mirror-like surface. An indenter tip was placed at different locations on the polished surface for the measurements using a nanoindentation system (Fischerscope, H100C-XYp) at room temperature. The load for the indentation with a Vickers indenter was $5 \mathrm{mN}$.

\section{Results}

\section{Plant anatomy}

Hichiriki reeds. Figure 3 shows light micrographs of the canes collected from the five reed beds mentioned above. The images in (a), (b), (c), and (d) are of specimens from the Kitakami River near Sendai (Spe. 1), the Watarase River near Nikko (Spe. 2), the Turumi River in Tokyo (Spe. 3), the Uji Rever in Kyoto (Spe. 4), respectively, and the images in (e) and (f) are from
Udono along the Yodo River (Spe. 5-1 and 5-2). As seen in Figure 3(e), the outermost part of the cane is enclosed by epidermis (Ep) comprising monolayer of cells, and the inside of $E p$ is cortex (Cor) composed of several layers of cells. The cells in Ep and Cor are small in diameter and have thick cell walls. The central cylinder $(C c)$ may be divided into three zones from Cor to pith cavity $(P c)$. They are composed of cells with thin cell walls $(C t)$, sclerenchymatous cells $(S c)$ with thick walls, and parenchyma cells $(\mathrm{Pa})$ with larger diameters compared to $C t$ and $S c$. The size of $\mathrm{Pa}$ decreases as the cell gets closer to $P c$. Vascular bundles $(V b)$ are distributed in $C c$. Each $V b$ is enclosed by cells with thick walls, which form a vascular bundle sheath $(B s)$. The $B s$ is called a fiber ring from the shape of its transverse cross section [10]. The plant $P$. australis almost resembles $A$. donax in plant anatomical characteristics as previously reported [10-12], but is different not only in scale of outer shape but also size of cells, as their English names of 'common reed' for $P$. australis (see Figure 2(b)) and 'giant reed' for A. donax imply. This is a reason why $A$. donax cannot be used for rozetsu.

Specimen 5-2 harvested from Udono shown in Figure $3 \mathrm{f}$ is a reference for an undesirable cane that the hichiriki player didn't choose after evaluating the cane because it exhibited "a bad complexion and over thickness." From the images in Figure 3, the wall thicknesses $T$ were estimated to be 1.01, $1.44,1.39,1.16,1.00$, and $1.36 \mathrm{~mm}$ for Spe. 1, Spe. 2, Spe. 3, Spe. 4 , Spe. 5-1, and Spe. 5-2, respectively. All the samples have a similar structure of cellular tissue indicated in Figure 3(e), although Spe. 2 (Watarase), Spe. 3 (Turumi), and Spe. 5-2 (Udono) have a wall too thick to make a rozetsu. The appropriate wall thickness of canes for a rozetsu is $T=\sim 1 \mathrm{~mm}$ according to the preference that the hichiriki player usually chooses.

Specimen 5-1 (Udono) was the best of the materials for rozetsu evaluated by the hichiriki player, and we compared it with the other samples. It was found that i) the thickness of the cell wall of $\mathrm{Pa}$ in $\mathrm{Cc}$ in Spe. 5-1 is almost the same as that of Spe. 3 (Tsurumi) but thicker than those of Spe. 1 (Kitakami), Spe. 2 (Watarase), Spe. 4 (Uji), and Spe. 5-2; ii) the thickness of the Ctzone in Spe.5-1 is almost the same as that of Spe. 4 but thicker than those of the other samples; iii) $B s$ is not as developed in Spe. 5-1 compared with the other samples; iv) the density of $\mathrm{Vb}$ (numbers/unit area) is larger in Spe. 5-1 than Spe. 3 but smaller than the other samples; v) the $\mathrm{Pa}$ zone in the innermost layer becomes thicker in Spe. 5-1 as well as Spe. 2 and Spe. 3; vi) the Sc zone in Spe. 5-1 is thin compared with those in the other samples, consisting of a thin wall of $T=1.0 \mathrm{~mm}$ for the good hichiriki reed. From these observations it is revealed that $S c$ cells are not 

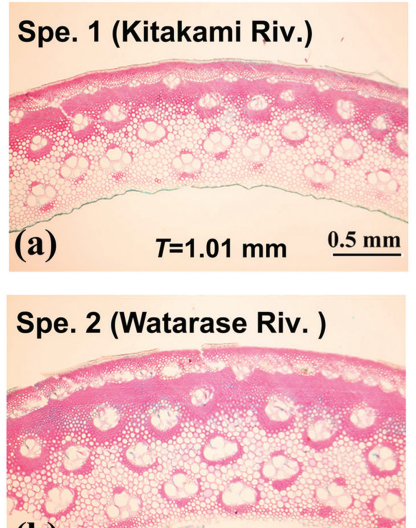

(b)

$T=1.44 \mathrm{~mm}$

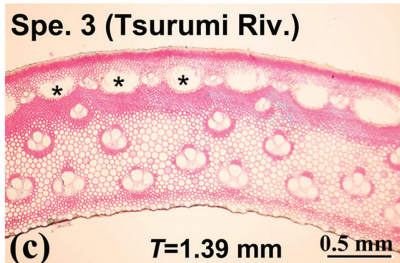

(c)

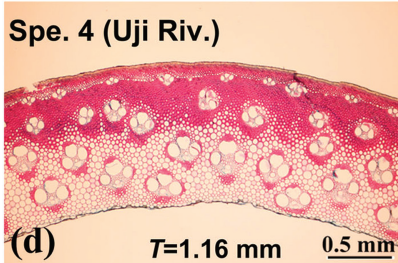

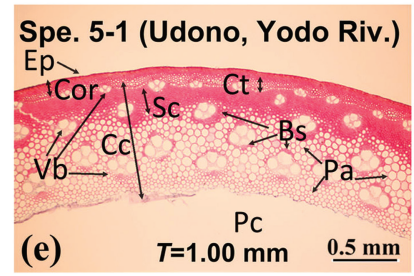

Spe. 5-2 (Udono, Yodo Riv.)

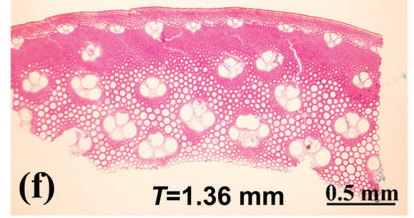

Figure 3: Light micrographs of $P$. australis canes from different reed beds. (a) Specimen 1 is from the Kitakami River near Sendai; (b) Specimen 2 is from the Watarase River near Nikko; (c) Specimen 3 is from Turumi River in Tokyo; (d) Specimen 4 is from the Uji Rever in Kyoto; and (e-f) Specimens 5-1 and 5-2 are from Udono. Ep: epidermis. Cor: cortex. $\mathrm{Vb}$ : vascular bundle. Bs: vascular bundle sheath. Cc: central cylinder. Pa: parenchyma cell. Ct: cells with thin cell wall. Sc: sclerenchymatous cells. Pc: pith cavity. The diameter of a cane is $\sim 11 \mathrm{~mm}$, making a circumference of $\sim 34 \mathrm{~mm}$ so that the observed area is about one-tenth of a whole cross section.

as developed in Spe. 5-1; both the walls of $\mathrm{Pa}$ cells enclosing $B s$ and the walls of $C t$ cells in the inside of Cor are thicker. Rozetsu (shown in Figure 4(a) and (b) as well as Figure 1(b)) is shaped so as to have double-thin blades where the outer part from the Ep layer to the $S c$ zone are shaved off [14]. The music performance or the acoustic vibration of the double reed may depend on the structure of the blades constructed with $P a, V b$, and $B s$ in the inner part of the cane of its thickness around $1 \mathrm{~mm}$, accordingly. In the Udono cane (Spe. 5-1), there are hard tissues such as Ep, Cor, $S c$, and $B s$ and soft tissues such as $P a$ and $V b$ with thicker cell walls uniformly distributed. By such particular growth, the reed has more uniform hardness in the whole blade because the thicker cell walls can be as hard. This will be discussed later with the results of hardness measurements done at those locations on the specimens. Hence, we concluded that the homogeneous structure over the hard and soft tissues would be an important condition for an excellent rozetsu.

Clarinet reeds. We also observed clarinet reeds [15] and found that the acoustic quality of a clarinet reed is mainly ascribed to the shape and configuration of the $V b$ bundles with $B s$, as well as the networks of the surrounding $P a$ cells. Each $B s$ tube enclosing $V b$ bundle works like a string for vibration, running along the reed. A reed with good musical performance has homogeneously distributed $V b$ bundles that provide the balance or symmetry of the local rigidity. This is necessary for good vibration, in particular on the blade tip of the reed. With the good acoustic double-reed rozetsu, each blade might vibrate smoothly and resonate as one body along their surfaces. So a homogeneous structure is required for resonance of the rozetsu blades. The quality is very different among canes even grown in the same place and among parts of the same cane. Agood cane for rozetsu should have an outer diameter of about $11 \mathrm{~mm}$ to fit it in the hichiriki tube, a wall thickness of about $1 \mathrm{~mm}$ to make its double blades, and a homogeneous structure to transmit good vibration. Hichiriki players say that it has become harder and harder to get good canes for reed material, similar to the situation of clarinet and oboe players using Arundo donax reeds. However, it is certain that good mance (excellent); R 5-2, a used reed
made of a part of cane away from a node, felt a little soft. It canes are still cultivated in Udono but may be scarcely found in other reed beds.

Biomechanics. Four pieces of practical rozetsu, handcrafted and provided as typical samples by the hichiriki player, were used for biomechanical measurements (Figure 4). Samples R 5-1, R 5-2, and $R$ 5-3 were made out of canes grown at Udono, and sample R 1-1 was from a cane grown at the reed bed along the Kitakami River.

Reed playability. The player's comments about the performance of the reeds that were used to prepare the samples are as follows: $\mathrm{R} \mathrm{5-1}$, a well-used reed (shown in Figure 4a), felt as if it were of light material. It exhibited good musical perforcould make a sound but could not be blown strongly (good); R 5-3, an unused, slightly thin reed made from harder cane near a node, would make a good sound while being used (excellent); R 1-1, an unused reed made on trial, was a little salty and smelled like grass. The material felt thin and hard, and the sound was clear but also thin and hard. Contrary to expectations, R 1-1 may not be so bad in the performance. Those comments and feelings for the unused reeds, R 5-3 and R 1-1, were based on her trial of blowing on them and her long-standing experience.

Microstructure and mechanical tests. Light micrographs of the cross sections of the bottoms of these samples are shown in Figure 4b. Although these images are of only modest quality, as compared with the micrographs of the specimens cut with the microtome shown in Figure 3, we can still identify the tissue features. The local indentation hardness $H_{\mathrm{IT}}$ and Young's modulus $E_{\mathrm{IT}}$ were measured at different tissue features marked 1 to 4 corresponding to $S c, B s, P a$, and $V b$, respectively, and the results are shown in Figures $4 \mathrm{a}$ and $4 \mathrm{~b}$. The tests revealed the following: i) In all the samples, $S c$ and $B s$ exhibit higher $H_{\mathrm{IT}}$ and $E_{\mathrm{IT}}$ than $P a$ and $V b$, which is natural because $S c$ and $B s$ are known to be harder features, and $P a$ and $V b$ are softer features. Accordingly, the indentation measurement can be qualitatively used for these materials. ii) $H_{\mathrm{IT}}$ and $E_{\mathrm{IT}}$ of the used reeds ( $\mathrm{R}$ 5-1 and $\mathrm{R}$ 5-2) are higher than those of the unused reed (R 5-3 and R 1-1), indicating that the tissues in rozetsu become harder and tighter as the reeds are played during the musical performances. The raw materials for rozetsu would be expected to have hardness and rigidity as low as the values for R 5-3 or R 1-1. Players say that rozetsu becomes softer as it is used. The term "soft" might be different in meaning between the physical property and the musical performance. iii) In comparison with R 5-2 (the well-used, good reed of Udono), R 5-1 (the well-used, excellent reed of Udono) has softer $B s$ and harder $P a$ and $V b$; that is, the difference of $H_{\mathrm{IT}}$ (and $E_{\mathrm{IT}}$ ) between the hard materials $(B s)$ and soft materials $(P a$ and $V b)$ is not so large. $H_{\mathrm{TT}}$ and $E_{\mathrm{TT}}$ for $S c$ at measured point 1 in R.5-2 are abnormally large. However, they do not need to be considered when we discuss the acoustic performance of the 

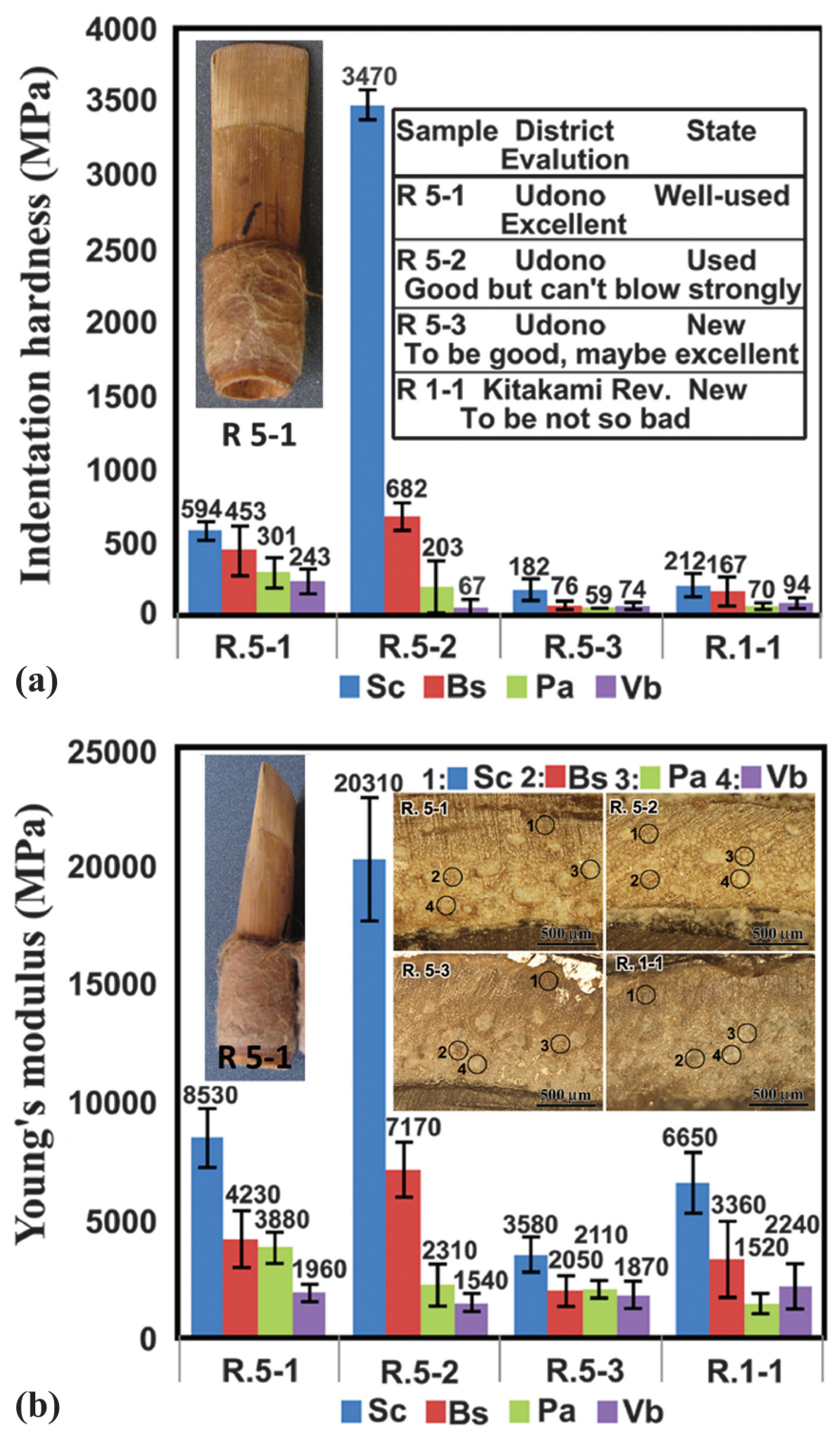

Figure 4: (a) Indentation hardness. (b) Indention Young's modulus. Measurements were performed on different tissue features (shown in the inset in (b)) of different rozetsu (indicated in the inset in (a)). Photographs of rozetsu R 5-1 are shown in (a) and (b).

reed because the $S c$ zones are not included in the blades. This is similar for R 5-3 (Udono reed) as compared with R1-1 (Kitakami reed). In fact, the assessment of the player was a little different; she found the former to be excellent and the latter to be not so bad.

\section{Discussion}

The biomechanical measurements are consistent with the conclusion from the plant anatomy-that homogeneity of the structure over the harder and softer materials is higher for an excellent rozetsu. The vibration is mainly influenced by the fiber tubes $B s$ passing through from the bottom to the top of the reed, enclosed by $\mathrm{Pa}$ cells. It is natural that the homogeneous distribution of $\mathrm{Vb}$ with $B s$ and the homogeneity of hard and soft tissues are favorable for the vibration of the rozetsu blades. It may be noted that we cannot say what hardness and rigidity are best for rozetsu because they depend on the player, the type of music, and other factors.

\section{Conclusion}

To understand why the best canes of $P$. australis for hichiriki reeds, rozetsu, have been provided only from Udono for more than 1,200 years, plant anatomy and morphology were examined for selected canes of $P$. australis that were harvested from the different reed beds in Japan, and the local indentation hardness and Young's modulus of tissues on the cross-sections of some representative rozetsu were measured. It is concluded that the good canes for rozetsu have an outer diameter of about $11 \mathrm{~mm}$ to fit the rozetsu into the hichiriki tube, a wall thickness of about $1 \mathrm{~mm}$ to form the blades for the reed, and comparatively homogeneous structure where harder materials such as sclerenchymatous cells $(S c)$ and vascular bundle sheaths $(B s)$ with hard cell walls are orderly deployed with softer materials such as parenchyma cells $(\mathrm{Pa})$ and vascular bundles $(\mathrm{Vb})$, in particular. This structure exhibits smaller differences in hardness and in Young's modulus between the hard and soft tissues, allowing the rozetsu blades to vibrate smoothly and provide the best musical performance. Good $P$. australis canes for rozetsu can be still harvested in Udono but are difficult to find in other reed beds. It is not so easy to describe quantitatively or objectively the relation between the structure of musical instruments and the musical tones or sounds because the latter is evaluated subjectively by the feeling and sensitivity of the players. The present paper is the first step in physically characterizing the hichiriki.

\section{Acknowledgements}

The authors deeply thank Ms. Hitomi Nakamura, a hichiriki player in the Reigakusha Gagaku Ensemble, for providing all the samples used in this investigation, the photographs in Figure 1, and valuable comments from a view of musical performance. The authors also thank Mr. Yuta Nakabuse for assistance in biomechanical measurements. Special thanks are due to Prof. Charles Lyman for carefully reading the manuscript and providing invaluable advice.

\section{References}

[1] UNESCO, http://www.unesco.org/culture/ich/en/RL/ gagaku-00265.

[2] More knowledge about hichiriki is available here: CCRMA, Department of Music, Stanford University, Orchestration in Gagaku Music, "Hichiriki," https://ccrma.stanford. edu/groups/gagaku/woodwinds/hichiriki.html.

[3] M Schuring et al., Pipers 381 (2013) 10-16.

[4] J Backus, J Acoust Soc Am 33 (1961) 806-09.

[5] SE Stewart and WT Strong, J Acoust Soc Am 68 (1980) 109-20.

[6] AH Benade and SN Kouzoupis, J Acoust Soc Am 83 (1988) 292-04.

[7] J Gilbert et al., J Acoust Soc Am 86 (1989) 35-41.

[8] T Idogawa et al., J Acoust Soc Am 93 (1993) 540-51.

[9] A Hirschberg et al., J Phys 4 (1994) 559-68.

[10] P Kolesil et al., Annals Botany 81 (1998) 151-55.

[11] CE Lawton et al., eds. Recent advances in wood anatomy, Forest Research Institute, Rotarua, New Zealand, 1996) 308-15.

[12] H-Ch Spatz et al., Phil Trans R Soc Lond B 352 (1997) 1-10.

[13] M Kawasaki et al., Microsc Res Tech 78 (2015) 260-67.

[14] See H Nakamura, https://www.youtube.com/ watch?v=8wMaFVH6aNE.

[15] Unpublished work. 


\title{
creating the best environment for microscopy...
}

\section{high performance anti-vibration platforms and workstations}

Our state-of-the art workstations and platforms are the result of many years of development. They provide the user with a truly vibration-free surface on which to place equipment. Our products are available in a wide range of sizes and shapes to support instruments of varying weights and footprints.

\section{- $2 \mathrm{~Hz}$ natural frequency built-in air isolators \\ Active self leveling and passive pump up versions \\ Highly rigid laminated construction with damping core}

\begin{abstract}
Low cost, easy to install and free from maintenance
- Ideal for laboratories and clean rooms, will meet Class 10 (Class 1 available)

- Simple, compact, easy to use and clean
\end{abstract}

\section{a wide range of styles, sizes, options and accessories...}

\section{Active Platforms: AMF Series}

Self-leveling and ideal for use when loads on the platform are likely to change.

\section{Passive Platforms: AMP Series}

Designed to be pumped-up and left alone. Ideal for use with fixed loads or in applications where pressurized air or gas cannot be used.

Side Tables: AMT Series

In a wide range of sizes and finishes..

Isolation Platforms: AMS Series

For heavy instruments.

\section{Balance Tables: AMB Series}

Weighted to $25 \mathrm{~kg}$ and are for use with light instruments such as balances.

High Load Workstations: AMH Series Designed for heavy instruments such as electron microscopes, which require high degrees of isolation from vibrations.

\section{Contoured Platforms: AMC Series}

Light and compact passive platform specially designed for instruments such as microscopes.

\section{please contact us for more information}

\section{Electron}

Migroscopy sciences
P.O. Box 550 - 1560 Industry Rd. • Hatfield, Pa 19440 Tel: (215) 412-8400 - Fax: (215) 412-8450 email: sgkcck@aol.com or stacie@ems-secure.com wuw.emsdiasum.com a better working environment

Workstations provide a tailored working environment as well as featuring an isolation platform built into the work surface, making working with a microscope both faster and easier, leading to more reliable measurements in your laboratory. Platforms can also be used stand alone beneath microscopes to isolate them from external disturbances and speed up measurement.

\section{flexible solutions}

We offer a range of workstations and platforms to suit different environments and microscope performance levels. Workstations feature a platform mounted on a study steel frame with height adjustable leveling feet and guards to protect the table from accidental knocks during use.

\section{ergonomic design}

The ergonomic workstation design minimizes user stress. With the active area option microscope platforms sit flush with the work surface and the surrounding area is useable for general work. Frames have height adjustable leveling feet for stability and user comfort with

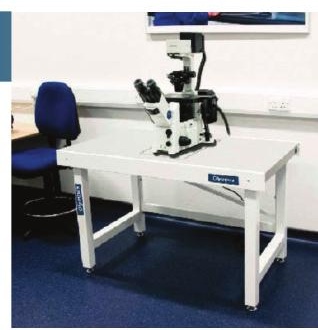
retractable castor feet, frame shelf and monitor support optional.

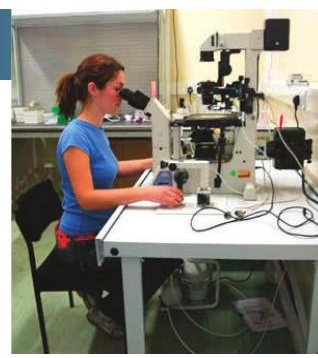

